\title{
Andarilhos de estrada e os serviços sociais de assistência
}

\author{
Euripedes Costa do Nascimento - Universidade Estadual Paulista, Assis, Brasil \\ José Sterza Justo - Universidade Estadual Paulista, Assis, Brasil
}

\begin{abstract}
Resumo
Este artigo tem por finalidade discutir os serviços assistenciais que algumas instituições oferecem aos andarilhos de estrada, procurando refletir, também, o que eles representam no contexto social contemporâneo. Participaram desta pesquisa quatro dirigentes de instituições assistenciais no Estado de São Paulo, por meio de um roteiro de entrevista semi-estruturado. Os dados foram analisados a partir da técnica de análise de conteúdo. Os relatos mostraram que os serviços oferecidos se estruturam de acordo com os interesses políticos do Estado na administração e fixação desses sujeitos para os territórios da marginalidade social onde o saber médico exerce uma função estratégica sob essas subjetividades. Os resultados indicam a necessidade de ampliar o debate em torno das políticas assistenciais a fim de se implementar um serviço desvinculado da tendência homogeneizadora do saber médico, levando em consideração os próprios indivíduos portadores de história e singularidade sem a incidência da normalização.

Palavras-chave: Andarilhos; Análise institucional, Psicologia social; Serviço social.
\end{abstract}

\section{Highway wanderers and the social work services}

\begin{abstract}
This paper aims to discuss the social work services that some institutions offer to Brazilian highway wanderers, searching to reflect on what they represent in the contemporary social context. This research was accomplished with four managers of help institutions in the state of São Paulo through semi-structured interviews. The data was analyzed using the content analysis technique. The results showed that help services are structured according to State political interests on administration and fixation of these individuals to the social exclusion territories where medical knowledge has a strategic function under these subjectivities. The results indicate the need to enlarge debate around help policies in order to implement a disentailed service of medical knowledge that homogenizes everybody in the social spaces, considering also the history and singularity of the individuals themselves without the impacts of normalization.

Keywords: Wanderers; Institutional analysis; Social psychology; Social work.
\end{abstract}

\section{Andariegos de carretera y los servicios sociales de asistencia}

\section{Resumen}

El objetivo de este artículo es discutir los servicios de asistencia social que algunas instituciones ofrecen a los andariegos de carretera brasileños, procurando refletir también lo que ellos representan en el contexto social contemporáneo. La pesquisa fue realizada con cuatro dirigentes de instituciones de ayuda del Estado de São Paulo por medio de entrevistas semi-estructuradas. Usando la técnica de análisis de contenido, los informes mostraran que los servicios ofrecidos se estructuran según los intereses políticos del Estado en la administración y fijación de estos individuos a los territorios de la exclusión social donde el saber médico tiene una función estratégica bajo estas subjetividades. Los resultados indican la necesidad de agrandar el debate alrededor de las políticas de ayuda para llevar a cabo un servicio desvinculado del saber médico que homogeneiza a todos en el espacio social, considerando también la historia y singularidad de los propios individuos sin los impactos de la normalización. Palabras-clave: Andariegos; Analisis institucional; Psicologia social; Asistencia social.

\section{Introdução}

Os andarilhos de estrada representam, no contemporâneo, um grupo de indivíduos que fazem longas jornadas a pé pelas principais malhas rodoviárias do país sem qualquer itinerário geograficamente preestabelecido. Diferente da maioria dos itinerantes, que escolhe o percurso em função das oportunidades de trabalho, a errância dos andarilhos não determina o trajeto a ser percorrido, porque eles não têm destino certo e definido ao perambular pelas estradas. Vale destacar que a errância radical dos andarilhos de estrada comporta uma multiplicidade de fatores desencadeantes. Pesquisas têm indicado a existência de fatores socioeconômicos (desemprego, ausência de moradia, migração e desestrutura familiar) inter-relacionados com fatores socioafetivos (desilusão amorosa, morte dos pais, violência familiar, desejo de liberdade) e fatores psicossociais (doença mental, abuso de álcool e drogas) como um dos principais motivos para a ruptura dos andarilhos com os nichos de fixação social (Brognoli, 1997; Di Flora, 1987; Dornelas, 1997; Justo \& Nascimento, 
2005, 2012; Mattos, 2006; Nascimento, 2008; Nascimento \& Justo, 2000; Peres, 2001; Rangel, 1997; Snow \& Anderson, 1998).

Embora a maioria dos andarilhos de estrada carregue consigo as histórias de vidas e as lembranças das experiências vividas nos nichos de fixação social, a grande referência identitária desses indivíduos é o trecho, porque se reconhecem e são reconhecidos fundamentalmente por habitarem esse espaço de trânsito, ou seja, as rodovias por onde realizam suas perambulações incessantes ao longo do ano (Justo, 2011; 2012; Justo \& Nascimento, 2012; Nascimento, 2008). Quando recorrem às instituições assistenciais inscritas no perímetro urbano das cidades, permanecem nelas por um período máximo de dois dias porque, preferem as adversidades das estradas a qualquer forma de aprisionamento do eu.

Nesse contexto, as instituições assistenciais servem para eles apenas como "casas de passagem", pois, entre uma perambulação e outra, boa parte deles só acorre a essas instituições em busca de algum auxílio para minimizar seus sofrimentos mais gritantes, principalmente aqueles vinculados à fome ou enfermidades contraídas pelo modo radical de viverem o cotidiano das estradas (Justo, 2011, 2012; Nascimento, 2008, 2012).

No contexto das instituições assistenciais, a estrutura do serviço comporta, ainda, uma série de normas, regras, deveres e procedimentos com os quais os andarilhos precisam se submeter para serem atendidos. Alguns pesquisadores são unânimes em apontar que disciplina, silêncio, obediência a horários e submissão ao assistente social, por exemplo, fazem parte das atividades do dia a dia na maioria das instituições públicas nais quais os dirigentes são investidos de poder, com direito de decidir sobre a vida de cada sujeito (Alves, 2009; Nasser, 2001; Rosa, 2005; Vieira, Bezerra \& Rosa, 2004).

Apesar das instituições assistenciais serem as principais referências para os andarilhos em momentos de extrema necessidade, pouco se tem explorado na literatura especializada quanto aos serviços oferecidos junto a esses indivíduos, o que justifica, portanto, o objetivo deste artigo. Não se discute, por exemplo, o que esses serviços assistenciais representam para o conjunto da população e muito menos quais os interesses que o Estado tem na perpetuação desses serviços. Se por um lado esses serviços assistenciais são vistos por algumas pesquisadoras como práticas de um saber alienado repleto de atividades serializadas (Alves, 2009; Martinelli, 2001; Rosa, 2005), por outro lado, os estudos de Michel Foucault $(1979,1995,2008)$ apontam para uma relação de saber e poder articulada com a normalização social como estratégia de manutenção e distribuição desses indivíduos pelos espaços desterritorializados, visando manter a soberania do Estado no governo das condutas.

$\mathrm{Na}$ perspectiva marxista, Martinelli (2001) destaca que a prática do serviço social sempre esteve subordinada à classe burguesa, porque se submetia à ideologia do capitalismo, que transforma os seres humanos em seres coisificados e absolutamente alienados, além de criar a ilusão de status social a ser conquistado pela força produtiva de trabalho. Segundo a autora, a classe dominante encontrou no serviço social uma importante ferramenta de manobra das massas, porque boa parte desses profissionais, ao se entregarem às práticas alienantes, endossa a dominação e o controle dos interesses do Estado e abstém-se da transformação histórica dos sujeitos em atores sociais.

Essas considerações são também observadas por Alves (2009), ao destacar que a ausência de conscientização histórica e social levou essa categoria profissional a produzir uma prática alienada, alienante e alienadora, cujo resultado é a incapacidade de responder às contradições e aos antagonismos encravados no cerne dos modos de produção capitalista. Nesse sentido, Alves (2009) salienta que a assistência social parece servir como instrumento de reificação, cujo objetivo é transformar os seres humanos em seres semelhantes a coisas que não se comportam de forma humana, mas conforme as leis do mundo das coisas. Trata-se, portanto, da forma mais radical e generalizada de alienação, na qual a ideologia imprime suas características mais acentuadas nos modos de ser, viver e sujeitar-se do indivíduo na sociedade capitalista.

Contudo, o serviço social de assistência pode ser pensado na perspectiva foucaultiana como uma ferramenta estratégica a favor da normalização social, compreendida como um mecanismo sutil de controle resultante do entrecruzamento nos campos de força do saber e do poder que se exerce na invisibilidade do espaço social pela comparação das desigualdades e naturalização das diferenças, onde a normalidade e anormalidade, inclusão e exclusão, por exemplo, são condições fundamentais para a sustentabilidade, o equilíbrio e a eficácia do biopoder (Foucault, 1979, 1984, 2008). No entrecruzamento desses campos, encontram-se dispositivos ou aparelhos disciplinares que impingem, tanto no sujeito quanto no corpo, uma série de procedimentos atrelados a obrigações e deveres, obediência e submissão, com a finalidade de torná-lo dócil e produtivo (Foucault, 1984). 
Desse modo, a normalização social trabalha na lógica da individualização fazendo o sujeito voltar-se sobre si mesmo, a fim de se reconhecer e se distinguir dos demais (Ewald, 1993; Foucault, 2008). As relações estabelecidas por ele nessa sociedade disciplinar são determinadas pelos efeitos de poder da ação normalizadora, que se enraízam no conjunto social e sancionam o tipo de comportamento que deve se submeter e adequar (Rabinow, 1999). Nesse sentido, podemos conjeturar que a assistência social se configura nesse contexto como um dispositivo normalizador a serviço do biopoder na operacionalidade, controle e distribuição das multiplicidades humanas.

No caso dos andarilhos de estrada, especificamente, isso significa dizer que a ação normalizadora opera nessa lógica de funcionalidade e os coloca em movimentação pelas rodovias, por ser um lugar onde não oferecem perigo ao status quo social (Nascimento, Justo \& França, 2009). A errância, aliás, representa aqui a efetividade da norma, pois, no processo normativo, o que ocorre é uma equiparação entre coisas contrastantes, e esse procedimento possibilita o trabalho de homogeneização e uniformização das heterogeneidades, garantindo sua continuidade.

É nesse sentido que o biopoder expande sua ação aos programas de bem-estar social e profissionaliza o serviço assistencial para servir de ferramenta de manobra aos interesses políticos do Estado, no sentido de manter as estratégias de controle e administração dos corpos na vida em sociedade. Mediante tais considerações, esta pesquisa teve como objetivo verificar quais os serviços que algumas instituições assistenciais prestam no atendimento aos andarilhos de estrada, procurando refletir, também, sobre o que essas ações representam no contexto social contemporâneo.

\section{Método}

Para a realização deste trabalho, utilizamos a abordagem qualitativa em pesquisa pelo fato de proporcionar uma compreensão significativa de como os indivíduos percebem a realidade e por ser também uma forma adequada para entender a natureza de um fenômeno social tal como é vivido e percebido pelos seus próprios atores. (Richardson, 2010).

\section{Participantes}

Esta pesquisa contou com a colaboração de quatro dirigentes assistenciais, por serem os responsáveis diretos pelas informações acerca do assunto a ser discutido neste artigo em particular, ou seja, os serviços assistenciais oferecidos por essas instituições junto aos andarilhos de estrada. A condução desta pesquisa foi efetuada somente após a aprovação formal do Comitê de Ética em Pesquisa (parecer 36/2009).

A pesquisa foi realizada em quatro instituições assistenciais no Estado de São Paulo. Foram selecionadas duas instituições públicas administradas diretamente pelas prefeituras municipais e outras duas administradas por entidades filantrópicorreligiosas, compreendendo uma do segmento católico e outra do segmento espírita, para verificarmos se o tipo de gestão pode proporcionar serviços diferenciados de assistência. Levando-se em consideração as principais malhas rodoviárias que constituem os grandes corredores de passagem dos andarilhos pelo Estado de São Paulo, selecionamos as cidades de Campinas e Ribeirão Preto para comporem o eixo das instituições públicas e São Paulo e Bauru o eixo das instituições filantrópicas de orientação católica e espírita, respectivamente.

Com o objetivo de manter o anonimato das informações, bem como a privacidade dos entrevistados e o sigilo das próprias instituições, utilizaremos o código "E" para nos referirmos aos dirigentes "entrevistados", seguido da inicial do tipo de gestão e cidade, para demarcarmos as instituições pesquisadas genericamente. Assim, o código E1PC representa o dirigente da instituição pública de Campinas, E2PRP o dirigente da instituição pública de Ribeirão Preto, E3FB o dirigente da instituição filantrópica espírita de Bauru e E4FSP o dirigente da instituição filantrópica católica de São Paulo.

\section{Instrumento e procedimento}

O instrumento norteador desta pesquisa foi um roteiro de entrevista semiestruturado focalizando os seguintes tópicos: objetivos da instituição, principais normas de atendimento, tipo de serviços oferecidos e os problemas de saúde em comum apresentados pelos andarilhos de estrada. Para efeito de esclarecimento, analisaremos aqui apenas os tipos de serviços oferecidos que tematizam o assunto ora abordado.

Após a aplicação das entrevistas, os relatos foram analisados pela técnica da análise de conteúdo (Bardin, 1979). Tal técnica de análise consiste, resumida e fundamentalmente, nas seguintes etapas: transcrição na íntegra das entrevistas gravadas; leitura flutuante do corpus (pré-análise); análise temática, que consiste na separação e identificação dos temas abordados, após as várias leituras flutuantes do corpus, em unidades de 
registro (núcleos de sentido), visando agrupá-los, posteriormente, em categorias e subcategorias discursivas.

\section{Resultados e Discussão}

Há várias maneiras de se apresentar os resultados de uma pesquisa qualitativa utilizando a técnica de análise de conteúdo, conforme o estilo assumido pelos autores. No caso desta pesquisa, optamos por fazer uma discussão das subcategorias separadamente, após a apresentação dos relatos referentes ao mesmo conteúdo. Assim, mediante as várias leituras e releituras dos relatos dos dirigentes, foi possível identificar que os serviços oferecidos pelas instituições assistenciais se configuram por meio de duas subcategorias: serviços básicos e serviços alternativos, conforme explicitados a seguir.

Serviços básicos: os relatos dos dirigentes das instituições pesquisadas indicaram que o serviço oferecido é basicamente de ordem material, como uma troca de roupa, alimentação, banho e produtos de higiene pessoal. Pelo fato de os andarilhos e demais usuários não poderem permanecer por muito tempo nessas instituições, os serviços básicos constituem a assistência que podem oferecer aos mais necessitados no dia a dia das atividades de trabalho. Exemplos:

Além da alimentação, todos os dias os usuários recebem toalha de banho. Shampoo, sabonete, escova de dentes, aparelho de barbear e pentes são descartáveis e entregues para a pessoa quando chega neste albergue. Esse é serviço que o albergue pode oferecer a eles e aos andarilhos porque aqui ninguém pode ser tratado diferente mesmo eles gostando de serem da estrada... (E1PC).

A gente oferece alimentação, banho, roupas e uma triagem para ver o que as pessoas estão precisando de imediato... os andarilhos que passam por aqui só vêm em busca de comida e banho e nem ficam dois dias. Só uma noite e no dia seguinte, agradecem e pedem para deixar sair porque eles querem ir para as estradas que é o lugar deles... a assistência básica é acolher as pessoas e saber o que elas mais precisam, dando a elas o pernoite, a troca de roupas e alimentação... Então, a instituição tem trabalhado dessa forma: acolher cada um dentro de suas necessidades mais gritantes... (E2PRP).

[...] o atendimento que a gente oferece é aquele atendimento, assim, mais material mesmo num ambiente que podemos dizer acolbedor. No albergue não há tempo suficiente para se fazer um trabalho, assim, de profissionalização, mesmo porque o albergue é apenas para os itinerantes e não para morador de rua que têm vínculo na cidade... Em regra geral o serviço oferecido é alimentação e troca de roupa mesmo... a assistência é igual para todos e não dá para fazer mais que isso: café da manhã, sopa, banho, troca de roupa, calcado... Já os andarilhos, só se alimentam e vão embora, não querem saber de regras e a gente libera para irem adiante porque é de costume deles andarem por aí (E3FB).

A Casa oferece serviços de mesa, cama e banho, tanques para lavagem de roupa e ferro de passar... Essa é a assistência básica que oferecemos. Agora, quando chega um andarilho, ele mesmo não fica e pede para ir embora no dia seguinte. Então, não dá para fazer nada por eles, porque eles mesmos não querem ser ajudados. Ele vem, passa por aqui e pede uma comida e no dia seguinte pede para ir embora e, aí, temos que respeitar a sua vontade e o seu direito de ir e vir... (E4FSP).

Conforme podemos verificar nos relatos, os serviços básicos oferecidos se limitam a suprir as necessidades materiais dos andarilhos numa assistência pautada pelo emergencial. Esses relatos parecem indicar que, pelo fato de os andarilhos serem da estrada não é possível fazer muita coisa além do minimamente possível. Segundo alguns pesquisadores, esses serviços oferecidos estão pautados numa prática caracterizada pelo clientelismo assistencial que procura desenvolver suas atividades em conformidade com as conveniências sociopolíticas vigentes nos Estados e municípios (Alves, 2009; Martinelli, 2001; Nasser, 2001; Vieira e cols., 2004). Essas autoras explicam, a partir de uma abordagem marxista, que nessas práticas clientelistas não são considerados os direitos sociais dos indivíduos, porque o objetivo é manter a instituição uma relação de adesão e cumplicidade aos interesses sociopolíticos do Estado ou aos imperativos caritativos da filantropia comandados pelo capitalismo responsável pelas desigualdades sociais.

A esse respeito, Alves (2009) considera fundamental questionar quais são as condições sociais geradoras de pobreza e miséria, para que seja possível a implantação de um serviço mais abrangente, levando-se em consideração as subjetividades apresentadas por esses indivíduos com experiências de vidas diferentes, provindas de contextos regionais diferentes completamente ignorados pelas práticas assistenciais de cunho absolutamente material. As consequências de tais atividades, segundo essa autora, transformam esses sujeitos num eterno dependente das políticas assistenciais públicas ou filantrópicas, que acabam reproduzindo práticas voltadas apenas para as necessidades básicas de subsistências. Isso acontece, segundo a autora, pelo simples fato de as políticas assistenciais públicas e filantrópicas não se interessarem humanamente pelo sujeito 
protagonista dos serviços, porque, ao fomentar um sistema de codependência, retroalimenta a subordinação que caracteriza a cultura do assistencialismo brasileiro como uma prática reducionista, ao delimitar o atendimento apenas no pernoite, na alimentação e na higiene.

Alves (2009) salienta ainda que a prática assistencialista do serviço social desenvolve ações fragmentadas junto aos seus usuários, por se submeter aos interesses institucionais do Estado ou da filantropia, que controlam todos os sujeitos e os classificam simplesmente como necessitados de assistência. Nesse contexto, o serviço social parece perpetuar, segundo a autora, uma prática de pronto-atendimento, ao cumprir uma função eminentemente estratégica na "minimização" das desigualdades sociais pela recusa de efetuar reflexões críticas junto às superestruturas do poder e estimular o debate de ideias capaz de promover outros processos de subjetivação e conscientização histórica da própria profissão. Por essa linha de raciocínio, Alves (2009) considera que a questão essencial a ser problematizada na estrutura das instituições assistenciais não são os serviços básicos propriamente oferecidos, pelo fato deles serem importantes para as necessidades imediatas dos andarilhos e demais usuários, mas, ao contrário, refletir por que esses serviços se enraizaram dessa forma na própria estrutura institucional.

Segundo Martinelli (2001), isso acontece porque os serviços básicos presentes nas instituições assistenciais se prestam a vender sua força produtiva de trabalho sem reflexões críticas, reproduzindo, portanto, um efeito ilusório do real ao dar continuidade a um projeto de pronto-socorro junto a essa população necessitada, comandados pelos interesses do capitalismo. Nesse sentido, a autora salienta que a assistência social se condicionou a fazer um duplo jogo de interesse não somente do Estado, mas, também, da própria soberania da profissão, ainda dependente das desigualdades e das misérias humanas para se manter como ciência.

Em outras palavras, Martinelli (2001) considera que o serviço assistencial, ao transitar contraditoriamente entre as demandas do capital e trabalho, operando sempre com a identidade a ele atribuída pelo capitalismo como acolhedora da miséria, perdeu as possibilidades de construir formas singulares e autênticas na conscientização histórica de boa parte de seus profissionais, transformando-se, portanto, numa prática alienada e alienante sem o compromisso ético de transformação social. As consequências de tais alienações na prática assistencial repercutem, segundo Martinelli (2001), nos serviços básicos oferecidos, cuja finalidade é manter oculta da sociedade a miséria trazida pelos pobres, os doentes, os andarilhos e todos aqueles que o sistema capitalista se encarrega de expulsar para o território da não cidadania.

Por essa linha de raciocínio, os serviços básicos oferecidos reproduzem uma prática assistencial pautada pela acomodação e alienação no desempenho da atividade profissional, sem quaisquer propostas de aprofundamento na busca de soluções para os problemas enfrentados pelos indivíduos dependentes dessas instituições (Alves, 2009; Dornelas; 1997; Martinelli, 2001). De acordo com esses autores, enquanto o serviço social reproduzir os interesses sociopolíticos, seja do Estado, seja da própria filantropia, sua tendência é continuar sendo apenas uma ferramenta de demarcação da miséria aviltante sem engajamentos políticos que promovam outras possibilidades de ações solidárias.

Por outra linha investigativa, esses serviços básicos oferecidos podem constituir elementos estratégicos que o Estado utiliza para administrar, distribuir e controlar esses indivíduos por meio da normalização social. Segundo Foucault (1984), a normalização tem por finalidade estabelecer objetivos e procedimentos através de uma multiplicidade de efeitos totalizadores que fixa, unifica e separa os sujeitos objetivamente, demarcando, a partir daí, o lugar que cada um deve ocupar no âmbito social. Para que esse mecanismo entre em operatividade é necessário haver os contrastes sociais como, por exemplo, os incluídos e os excluídos, os loucos e os sadios, pois são eles quem garante e mantém o padrão de normalidade e anormalidade que atravessam os campos de força do poder e do saber, produzindo efeitos de verdade sobre todo um conjunto da população (Ewald, 1993; Rabinow, 1999).

Para Rabinow (1999), a normalização social serve, também, para controlar e isolar as chamadas "anomalias", presentes na sociedade, mediante procedimentos corretivos provenientes dos efeitos do biopoder, que sancionam o tipo de comportamento a que cada indivíduo deve se submeter e adequar. Isso significa dizer que a inclusão e a exclusão, por exemplo, são efeitos dessa sanção normalizadora que racionaliza as diferenças pela comparação e distribui os indivíduos objetivamente pelas diversas camadas de pertencimento social, para assegurar ao Estado o controle e o poder sob todo o comportamento da população (Nascimento e cols., 2009). Vista dessa maneira, a desigualdade social é utilizada pelo Estado como uma estratégia política para equilibrar os campos de força do poder e do saber, a 
fim de dar sustentabilidade e regulamentação aos seus elementos administrativos por todo o espaço social.

É nesse sentido que as instituições públicas e filantrópicas de assistência se configuram nesse contexto como um dispositivo normalizador a serviço do Estado na operacionalidade, controle e fixação dos andarilhos para os territórios da marginalidade. Nesse caso, a perambulação dos andarilhos pelas rodovias permite que o poder circule por todas as direções, aparentemente contraditórias, nos pólos positivos e negativos da vida em sociedade, vigiando e disciplinando cada indivíduo objetivamente. Por essa razão, é mais econômico para o Estado prover os mínimos recursos materiais de subsistência aos andarilhos e demais miseráveis, de toda sorte, que proporcionar outros processos de subjetivação, pois esses sujeitos são elementos estratégicos para suas ações biopolíticas (Foucault, 2008).

Isso explica, então, por que o Estado elabora e mantém os programas de bem-estar social e legitima o serviço assistencial como mecanismo de manobra dos miseráveis. Ou seja, não é politicamente interessante para o Estado erradicar as desigualdades sociais, pois isso poderia colocar em risco sua hegemonia administrativa e estimular as resistências correlatas presentes no entrecruzamento do poder e do saber. Portanto, o serviço básico oferecido pelas instituições públicas e filantrópicas de assistência, conforme os relatos de seus dirigentes, serve como tática política que o Estado utiliza para fixar os andarilhos no território da marginalidade, porque eles simbolizam o exemplo mais radical daquilo que a maioria da população deve evitar (Nascimento, 2012). Nesse contexto, alimentação, agasalho e pernoite, por exemplo, representam medidas políticas que o Estado utiliza para manter esses sujeitos sempre dependentes dos programas socioassistenciais e promover sua "preocupação" com a qualidade de vida de seus habitantes.

No caso das instituições filantrópicas fundamentadas na moral do cristianismo, vale acrescentar que esses serviços básicos oferecidos, além de assegurarem o poder do Estado e a operacionalidade da norma, atuam também como um dispositivo para manter a dessedentarização e a erraticidade dos andarilhos pelos não lugares das rodovias. Foucault (2008), ao analisar as relações de poder no pastorado cristão, esclarece que uma das finalidades dessas instituições é a salvação do indivíduo no outro mundo e, para tanto, não importam as condições sociais que cada indivíduo apresenta no mundo, pois o objetivo é fazê-lo se curvar sob si mesmo e se submeter ao poder transcendental de Deus.
Nesse sentido, a metáfora do pastor e a salvação do indivíduo no outro mundo, desenvolvida por Foucault, ganha conotações específicas nessas instituições assistenciais, uma vez que seus dirigentes não se interessam pelas ovelhas desgarradas dos laços sociais, tal como acontece com os andarilhos e tantos outros em situações semelhantes, pois a ideia é manter em circulação as estratégias de poder nas redes de inteligibilidade, para que haja sempre ovelhas perdidas, visando ao equilíbrio das campinas e à objetificação dos próprios sujeitos.

Desse modo, a distribuição de sopa ou comida (o bom pasto), marca registrada de qualquer instituição filantrópica, serve também como tática política no sentido de conformar o sujeito com sua própria situação miserável, em perfeita consonância com a proposta cristã, deixando-o seguir sua jornada errática como condição necessária e intransferível para o "aperfeiçoamento" espiritual no outro mundo (Foucault, 2008). Em outras palavras, o objetivo das instituições filantrópicas não é arrebanhar as ovelhas desgarradas, como os andarilhos, por exemplo, mas apascentar suas necessidades emergenciais e efetivar a errância pelas rodovias, fixando-os nesse território da marginalidade social, onde não representam perigo à ordem estabelecida, e pelo fato delas também serem um dos caminhos para se chegar até Deus.

Portanto, a questão a ser problematizada nas instituições públicas e filantrópicas de assistência não é os serviços básicos propriamente oferecidos - mesmo porque eles são necessários para a subsistência dos sujeitos albergados, mas com quais finalidades eles estão sendo oferecidos, ou seja, o que precisa ser questionado são as estratégicas sociopolíticas do Estado sob essas "vidas desperdiçadas" e dispersadas pelos territórios invisíveis da errância (Bauman, 2005; Brognoli, 1997; Di Flora, 1987; Dornelas, 1997; Justo, 2012; Justo \& Nascimento, 2012; Nascimento, 2008, 2012; Vieira e cols., 2004). Enquanto o serviço social não questionar essas tecnologias políticas de controle e manutenção dos miseráveis, das quais os andarilhos são os exemplos mais radicais, continuará se submetendo ao poder do Estado, além de perpetuar saberes que acreditam ser verdadeiros, sem os passarem pelas análises críticas e reflexivas nessas redes de inteligibilidade.

Serviços alternativos: além dos serviços básicos oferecidos, pudemos verificar que as instituições assistenciais oferecem outros tipos de serviços quando o andarilho e demais usuários apresentam algum problema de saúde física ou mental, tais como: terapia ocupacional, encaminhamentos para os ambulatórios, Caps e unidades de 
pronto atendimento. No caso das atividades de terapia ocupacional, elas são desenvolvidas com sujeitos que estão passando por algum tipo de tratamento médico prolongado (sem serem necessariamente andarilhos). Vale destacar que, embora não haja a presença física e constante do profissional de medicina, o saber médico circula nessas práticas assistenciais de forma objetivante. Exemplos:

O albergue oferece também acolbimento que é realizado com a psicóloga em atividades de terapia ocupacional. É feita também uma entrevista com a assistente social, que far. encaminhamento para outras instituições de saúde quando a pessoa apresenta algum distúrbio psiquiátrico ou é dependente de drogas psicoativas. Nesses casos, entramos em contato com o Caps ou o pronto-socorro e depois com os familiares, para ver se a familia vem e o leva para casa... (E1PC).

Os [andarilhos] que a gente consegue segurar, porque a maioria não fica, está em busca de chegar em algum lugar, alguma cidade, com aquela ideia fixa. Nós temos o trabalho de terapia ocupacional com os voluntários da USP, que estão vindo fazer um trabalho toda quarta e sexta. Aos domingos vem 0 pessoal da igreja evangélica, orar, tocar e cantar para eles... (E2PRP).

Em caso de doenças, são encaminhados para o pronto-socorro ou para os ambulatórios de saúde mental e, depois que melhoram, eles devolvem os andarilhos para nós e ai a gente vê para onde encaminha... No caso deles, a gente deixa eles irem adiante porque querem viver assim. Então, a assistência é igual para todos e não dá para fazer mais que isso... (E3FB).

Nós fizemos uma parceria com o PSF, que é o Programa de Saúde da Família. Ai a médica vem pelo menos uma vez por semana, fica aqui um tempo com os enfermeiro,s $e$ aqueles que apresentam problemas de saúde são encaminhados para tratamento no pronto-socorro ou no Caps, conforme cada caso, porque alguns que passam por aqui têm problemas mentais, muitos são dependentes de álcool e drogas... Essa é a assistência básica que oferecemos. Então, nós acolhemos eles [andarilhos] da mesma forma que os migrantes e damos assistência às suas necessidades de emergência. E pelo fato deles não quererem ficar na cidade, porque o lugar dele é a rua, as estradas, nós não faz̧emos um trabalho de inserção social, porque eles mesmos não aceitam... (E4FSP).

Conforme podemos constatar nesses relatos, parece ficar clara a presença do saber médico num pré-diagnóstico realizado pelos dirigentes (a maioria assistentes sociais) junto a andarilhos e demais usuários desses serviços, cujo procedimento padrão é encaminhá-los para tratamento em nível ambulatorial ou desenvolver atividades ocupacionais, conforme a situação apresentada por eles. Embora essas situações de enfermidade apresentadas pelos sujeitos sejam às vezes inevitáveis, exigindo intervenções médicas nos ambulatórios, por exemplo, chamam-nos a atenção que essas práticas assistenciais efetivam a dessedentarização dos andarilhos, porque, ao receberem alta do tratamento e retornando ao serviço social, são dispensados para continuarem a circulação pelas rodovias (Nascimento, 2012).

Nesse contexto, o serviço social se configura como uma prática assistencial de pronto-socorro, porque é mais prático, cômodo e rápido em determinadas situações despejar esses sujeitos para as rodovias ao invés de tentar compreender a história pessoal de cada um e encontrar alternativas para que possam viver a vida, sejam quais forem as circunstâncias apresentadas pelo sujeito. Assim, o encaminhamento dos andarilhos para as instituições de saúde, quando apresentam alguma enfermidade, mediante um diagnóstico precipitado realizado pelos próprios dirigentes (a maioria assistentes sociais), é resultado direto desse saber médico circulante no espaço institucional homogeneizador, cujo objetivo é normalizar as diferenças e ajustar os sujeitos conforme os interesses da biopolítica (Foucault, 2008).

Por essa razão, talvez seja mais prático encaminhar os sujeitos supostamente portadores de alguma enfermidade para os ambulatórios, unidades de pronto atendimento e Caps, por exemplo, que procurar compreender as causas de seus infortúnios, porque a medicalização da vida se tornou a maneira mais rápida e econômica para regular os sofrimentos na cultura do mal-estar da atualidade (Birman, 2000, 2006). Daí a importância conferida ao saber médico e à prescrição de medicamentos para manter os sujeitos, sejam quais forem suas enfermidades, sob controle e vigilância da norma dentro dos padrões socialmente aceitos pela cultura ocidental que elegeu o bem-estar físico e mental como sinônimos de felicidade e inclusão social (Foucault, 1995, 2008).

Para efeito de esclarecimento, vale ressaltar que esse saber médico emergiu a partir das práticas confessionais do catolicismo romano, segundo o qual quanto mais o indivíduo revelasse seus segredos mais íntimos, mais o sacerdote poderia explicitar as verdades sobre si mesmo. Segundo Foucault (1995), essas práticas confessionais adquiriram dimensões políticas a partir do momento em que a sexualidade tornou-se uma preocupação social, no século XIX, porque se acreditava que 
ela era a chave para a compreensão da saúde do indivíduo, sua identidade e suas anomalias. Foucault salienta que a sexualidade nesse período se tornou questão de ordem particular e o lugar originário da verdade na qual tais práticas confessionais exerciam a função de poder e saber sobre o corpo e a mente, no deciframento do eu do próprio indivíduo, se tornando, portanto, objeto de investigação científica.

Assim, uma ruptura entre sexo e sexualidade se operou no início do século XIX e possibilitou isolar esses dois conceitos para uma melhor administração e normalização do corpo do indivíduo. De acordo com Foucault (1995), a noção de sexo era uma questão de ordem familiar e estava relacionada com a ideia de casamento, procriação e transmissão da riqueza, enquanto a sexualidade era uma questão individual na qual $o$ indivíduo, ao confessar os segredos mais íntimos do eu no confessionário, poderia descobrir as verdades de si mesmo com o auxílio de um especialista na arte interpretativa.

A sexualidade passou, então, a ser considerada como a essência do ser humano individual e o núcleo de sua identidade pessoal na elaboração da verdade e do deciframento de si. A partir da confissão dos desejos ocultos do eu, buscando a verdade e o autoconhecimento, foi possível conhecer os segredos do corpo e da alma, e tais procedimentos proporcionaram às ciências médicas a apropriação desse discurso na elaboração de saberes "científicos" sobre o indivíduo, que delega agora ao especialista médico o poder de decidir sobre os dramas de sua subjetividade, ao lhe revelar a "verdade" de si (Foucault, 1988).

Desse modo, o corpo foi considerado o lugar da sexualidade por excelência, levando os saberes médicos a conhecer, nos menores detalhes, todos os segredos biológicos e psíquicos que o indivíduo guardava dentro de si. Essa ideia de um poder biológico sobre o corpo e a mente deu origem ao que Foucault (1984) definiu como biopoder e possibilitou o controle sobre a vida da população através das ações políticas e administrativas do Estado ou biopolítica. Portanto, a biopolítica é a operacionalização do biopoder e pode ser compreendida como uma tecnologia de ação capaz de produzir procedimentos, saberes e verdades nas relações do indivíduo consigo mesmo e com a sociedade, sustentado o corpo como objeto de investigação do poder.

A partir do discurso sobre a sexualidade foi possível, segundo Foucault (1988), identificar as anomalias individuais e controlar os desvios e as enfermidades presentes no espaço social. Essa medicalização do social possibilitou ao Estado o controle sobre a vida em sociedade, disseminando a saúde como estratégia política para a sua hegemonia, além de promulgar sentenças universais de normalidade, naturalizando seus discursos sobre o corpo e a mente, das quais as ciências humanas, onde se inclui o serviço social, se apropriaram como verdades inquestionáveis e as disseminam em seus campos de saber.

Segundo a análise de Castel (1987), o que está por trás dessa medicalização social não é o controle das patologias e do tratamento dos sintomas apresentados pelo indivíduo, mas o risco de determinados grupos se desviarem daquilo elaborado como norma comum de conduta, produzida historicamente no jogo de forças, para o suposto "equilíbrio" da ordem social. Desse modo, as estratégias médicas visam, sobretudo, à prevenção, que requer um rastreamento cuidadoso dos riscos no sentido de antecipar a eclosão de determinados comportamentos indesejáveis capazes de estremecer o controle e a vigilância da vida em sociedade.

De acordo com Castel (1987), o risco não se relaciona à existência de um determinado perigo, mas à probabilidade do aparecimento de comportamentos indesejáveis de determinados grupos de pessoas. Enquanto o perigo remete ao imponderável, porque não há como aplicar um cálculo de probabilidade, o risco, por outro lado, se insere dentro de uma ordem contida na ação humana deliberada, indicando a possibilidade de seu acontecimento, a partir do comportamento apresentado pelo indivíduo. Segundo o autor, essa vigilância não se inscreve nas técnicas disciplinares tradicionais, pelo simples fato de as políticas médico-preventivas da atualidade se dirigirem aos fatores de probabilidade e correlações estatísticas que decompõem os sujeitos concretos da intervenção e os recompõem a partir de uma configuração de elementos heterogêneos suscetíveis de produzir risco à ordem social.

Nesse contexto, a administração dos riscos e a medicalização do social podem ser compreendidas pelo efeito direto da biopolítica sobre o controle racionalizado da população, conforme as análises desenvolvidas por Foucault $(1987,1988,2008)$. Com a perda do poder do soberano e a constituição do biopoder na sociedade disciplinar, o Estado passou a ser o responsável pela gestão da população, e o saber médico se tornou o seu maior aliado no controle e na normalização da vida. Em decorrência disso, a medicina, como medida terapêutica e preventiva, transformou-se no modelo ideal para as demais ciências humanas que, inseridas no regime $\mathrm{da}$ 
norma e orientadas pelo exame, passam a funcionar por esse modelo de objetividade sobre o corpo e a alma.

Conforme podemos perceber, a medicalização do social foi o resultado dessa microfísica do poder que procura realizar a normalização da existência, disseminando a saúde e o bem-estar como critérios fundamentais para a vida em sociedade a partir da expansão do saber médico e biológico sobre o corpo (Foucault, 1979). Difundida nas várias ramificações do espaço social, foi a biologia que possibilitou à medicina estabelecer os padrões de normalidade e anormalidade a serem incorporados por outros saberes profissionais, efetivando, assim, a ideia de qualidade de vida sob os efeitos reguladores da medicalização (Birman, 2000, 2006).

Daí essa ideia de encaminhamento para ambulatórios e redes hospitalares estar presente nos discursos dos assistentes sociais, pois o que se pretende é a normalização dos sujeitos identificados como "portadores" de algum "distúrbio" mental produzido, às vezes, pelo abuso de álcool e drogas, verificado num dos relatos desta pesquisa, ou possuidores de outras enfermidades que precisam ser diagnosticadas e catalogadas pelo saber médico ou psiquiátrico e normalizadas pelo biopoder (Foucault, 1988; Birman, 2006). Isso nos possibilita considerar que as instituições assistenciais ocupam um lugar estratégico para as ações da biopolítica no controle da vida dos andarilhos e demais miseráveis, ao incorporar em seus discursos a ideia de encaminhar os sujeitos considerados enfermos do corpo ou da alma para as instituições de saúde, a fim se serem normalizados conforme os padrões socialmente impostos daquilo que se convencionou chamar como "qualidade de vida da população" sob a insígnia das vias medicamentosas (Nascimento, 2012).

\section{Considerações finais}

Embora os dados de nossa pesquisa estejam limitados a apenas quatro dirigentes de diferentes modelos de gestão assistencial, esses relatos nos possibilitaram considerar que os serviços sociais oferecidos aos andarilhos de estrada se configuram dentro de um modelo biomédico de intervenção na qual a medicalização da vida define boa parte de suas práticas assistenciais. Tanto as instituições públicas quanto as filantrópicas tendem a homogeneizar todos os indivíduos recorrentes aos seus serviços como uma única e mesma população de miseráveis, mantendo-se distantes dos problemas apresentados por eles em suas particularidades, cujo objetivo é oferecer apenas o pernoite, a alimentação e, eventualmente, o encaminhamento para as instituições públicas de saúde, quando apresentam algum tipo de "problema" físico ou psíquico (Rosa, 2005; Vieira e cols., 2004; Nasser, 2001). A maioria dos dirigentes dessa pesquisa parece ignorar, ainda, que cada subgrupo de indivíduos à margem da sociedade traz, em suas experiências de vida pelas ruas e rodovias, histórias diferentes, carecendo também de acompanhamentos diferentes relacionados à própria condição pessoal.

Desse modo, condicionados a desempenharem suas atividades pautadas na prática médica e desprovidos de relações interativas com esses sujeitos, os dirigentes institucionais endossam os interesses biopolíticos do Estado no controle dessa população. Os relatos parecem indicar, ainda, que a maioria vê a errância como um caminho sem volta, na qual o futuro é incerto demais para se pensar outras possibilidades de amparo ou uma assistência menos homogeneizadora junto às reais necessidades dos andarilhos e demais sujeitos em situações semelhantes. Nesse sentido, a normalização passa a incidir também sobre a movimentação de todos os indivíduos no espaço social, criando corredores e ritmos de circulação, mais do que pontos estáveis de estacionamento e ancoragem, sendo essas condições uma das características marcantes que assolam a sociedade brasileira contemporânea (Nascimento e cols., 2009).

No caso dos andarilhos, circunscritos nas malhas rodoviárias do país, eles fazem da perambulação constante sua condição exclusiva de existência, permitindo, assim, o exercício do poder e saber das instituições assistenciais, que normaliza, organiza, controla e distribui tais heterogeneidades para territórios geográficos ainda inabitados para a maioria da população. Nesse contexto, podemos dizer que as instituições assistenciais se configuram como uma ferramenta estratégica a serviço do biopoder, onde a norma exerce uma função fundamental na administração da vida desses sujeitos.

Portanto, o desafio que se coloca no contemporâneo é saber como propiciarmos outras possibilidades de atendimento para que os andarilhos tenham melhores condições de ser assistidos ao recorrerem a essas instituições nos momentos mais cruciais de suas existências. Isso exige, evidentemente, além de coragem e ousadia para desaprendermos o que nos foi ensinado como verdade, uma ampliação do debate em torno das políticas assistenciais, a fim de se implementar um serviço desvinculado da tendência homogeneizadora do saber médico, levando em consideração os próprios 
indivíduos portadores de história e singularidade num mundo ainda possível de ser habitado sem as incidências da normalização. Ou seja, o que precisa ser problematizado nesse modelo institucional de assistência é a própria prática objetificante do serviço social, que desconsidera as diferenças individuais, a favor de uma política homogeneizante dos corpos capturados e distribuídos nas redes de inteligibilidade do saber e do poder.

\section{Referências}

Alves, A. M. F. (2009). Assistência social: história, análise crítica e avaliação. Curitiba: Juruá.

Bardin, L. (1979). Análise de conteúdo. Lisboa: Edições 70.

Bauman, Z. (2005). Vidas desperdiçadas. São Paulo: Zahar.

Birman, J. (2000). O mal-estar na atualidade. Rio de Janeiro: Civilização Brasileira.

Birman, J. (2006). Arquivos do mal-estar e da resistência. Rio de Janeiro: Civilização Brasileira.

Brognoli, F. F. (1997). Trecheiros e pardais: trajetórias nômades. Travessia, 27, 29-32.

Castel, R. (1987). A gestão dos riscos. Rio de Janeiro: Francisco Alves.

Di Flora, M. C. (1987). Mendigos: porque surgem, por onde circulam, como são tratados? Petrópolis: Vozes.

Dornelas, S. M. (1997). O peixe e a rede: o migrante e o albergue no discurso dos responsáveis e funcionários da AVIN. Travessia, 29, 30-45.

Ewald, F. (1993). Foucault, a norma e o direito. Lisboa: Vega.

Foucault, M. (1979). Microfísica do poder. Rio de Janeiro: Graal.

Foucault, M. (1984). Vigiar e punir. Petrópolis: Vozes.

Foucault, M. (1987). O nascimento da clínica. Rio de Janeiro: Forense Universitária.

Foucault, M. (1988). História da sexualidade I. Rio de Janeiro: Graal.

Foucault, M. (1995). O sujeito e o poder. Em H. L. Dreyfus \& H. L. Rabinow (Eds.), Michel Foucault, uma trajetória filosófica (pp. 231-249). Rio de Janeiro: Forense Universitária.

Foucault, M. (2008). Segurança, território, população. São Paulo, Martins Fontes.
Justo, J. S. (2011). Andarilhos e trecheiros: errância e nomadismos contemporâneos. Maringá: Eduem.

Justo, J. S. (2012). Vidas errantes: politicas de mobilidade e experiências de tempo-espaço. Londrina: Eduel.

Justo, J. S., \& Nascimento, E. C. (2005). Errância e delírios em andarilhos de estrada. Psicologia: Reflexão e Crítica, 18(2), 177-187.

Justo, J. S., \& Nascimento, E. C. (2012). Road wanderers in Brazil: a study on modern psychosocial human mobility. International Journal of Sociology and Anthropology, 4(5), 165-171.

Martinelli, M. L. (2001). Serviço social: identidade e alienação. São Paulo: Cortez.

Mattos, R. M. (2006). Situação de rua e modernidade: as saídas das ruas como processo de criação de novas formas de vida na contemporaneidade. (Dissertação de Mestrado não publicada). Faculdade de Psicologia da Universidade São Marcos, São Paulo.

Nascimento, E. C. (2008). Nomadismos contemporâneos: um estudo sobre errantes trecheiros. São Paulo: Editora Unesp.

Nascimento, E. C. (2012). Errância no contemporâneo: um estudo sobre a percepção de dirigentes e profissionais de instituições assistenciais em relação a andarilhos de estrada (Tese de Doutorado não publicada). Faculdade de Ciência e Letras da Universidade Estadual Paulista, Assis, São Paulo.

Nascimento, E. C., \& Justo, J. S. (2000). Vidas errantes e alcoolismo: uma questão social. Psicologia: Reflexão e Crítica, 13(3), 529-538.

Nascimento, E. C., Justo, J. S., \& França, S. A. M. (2009). Errância e normalização social: um estudo com andarilhos de estrada. Psicologia em Estudo, Maringá, 14(4), 641-648.

Nasser, A. C. A. (2001). Sair para o mundo: trabalho, familia e lazer na vida de excluídos. São Paulo: Hucitec.

Peres, R. S. (2001). Andarilhos de estrada: estudo das motivações e da vivência das injunções características da errância. Psico-USF, 6(1), 67-75.

Rabinow, P. (1999). Antropologia da razão. Rio de Janeiro: Relume Dumará.

Rangel, M. C. (1997). Migrantes da casa de passagem de Presidente Prudente. Travessia, 29, 17-24. 
Richardson, R. J. (2010). Pesquisa social: métodos e técnicas. São Paulo: Atlas.

Rosa, C. M. M. (2005). Vidas de rua. São Paulo: Hucitec.

Snow, D. \& Anderson, L. (1998). Desafortunados: um estudo sobre o povo da rua. Petrópolis: Vozes.
Vieira, M. A. C, Bezerra, E. M. R., \& Rosa, C. M. M. (2004). População de rua: quem é, como vive, como é vista. São Paulo: Hucitec.

Recebido em: 04/04/2014

Reformulado em: 20/05/2014

Aprovado em: 15/06/2014

Sobre os autores:

Eurípedes Costa do Nascimento é doutor em Psicologia e Sociedade pela Universidade Estadual Paulista, Campus de Assis, integrante do Grupo de Pesquisa: Figuras e modos de subjetivação no contemporâneo, e professor na disciplina de Seminários de Pesquisa I no Programa de Pós-Graduação em Psicologia da Unesp/Assis.

José Sterza Justo é livre-docente pela Universidade Estadual Paulista, Campus de Assis, coordenador do Grupo de Pesquisa: Figuras e modos de subjetivação no contemporâneo, e professor nos cursos de Graduação e Pós-Graduação em Psicologia da Unesp/Assis.

Contato com os autores:

Universidade Estadual Paulista Júlio de Mesquita Filho

Av. Dom Antonio, 2100

Bairro: Parque Universitário

CEP: 19806-900 - Assis, SP 
